\title{
Endometrioid Stromal and Related Neoplasms of the Vagina
}

National Cancer Institute

\section{Source}

National Cancer Institute. Endometrioid Stromal and Related Neoplasms of the Vagina.

NCl Thesaurus. Code C40269.

A category of rare neoplasms that arise from the vagina. It includes low grade endometrioid stromal sarcoma and undifferentiated sarcoma. 